\title{
Research on Low Carbon Planning Method of Resource Based City Based on Coupling of City Region and Central City -- A Case Study of Xingtai City
}

\author{
Qinghua Liao ${ }^{1}$, Shengbin Liu ${ }^{2}$, Fangqin Zhao ${ }^{3 *}$ \\ 1. School of architectural engineering, Tongling University, Tongling 244061, China \\ 2. Beijing Wanda cultural tourism planning and Design Institute Co., Ltd, Beijing 100022, China \\ 3. Department of Traffic Management, Anhui Public Security Education Research Institute, Hefei \\ 230000
}

\begin{abstract}
Resource-based cities generally have "high energy consumption, high carbon emissions, and high pollution". Exploring low-carbon planning of resource-based cities means great significance for promoting the low-carbon transformation and development of resource-based cities and achieving "carbon peak" and "carbon neutrality". Based on the two levels of city region and central city, the paper proposes a low-carbon planning method for resource-based cities from four aspects: industrial transformation, land use, road transportation and ecological environment. At the city region level, it is necessary to reasonably determine urban industrial structure and industrial development scale, and meanwhile, optimize the industrial layout by reasonably planning production, living and ecological space and formulating practical space control measures; coordinating the connection between external traffic and traffic system within the city; constructing a carbon sink network composed of green patches-ecological corridors-peripheral matrix. At the central city level, it is necessary to analyze gradient attributes of carbon emissions from different land types, rationally arrange various types of construction land; optimize the layout of urban residence and employment space; increase systematicness of road planning in central urban areas; give full play to the carbon sink role of ecological corridors. Finally, an empirical study is carried out with the case of Xingtai City. The research can provide theoretical basis and path reference for reducing carbon emissions of resource-based cities through spatial planning.
\end{abstract}

Keywords: City region, central city, resource-based city, low-carbon planning, Xingtai City

\section{Introduction}

Since the founding of the People's Republic of China, under the country's vigorous support for the development of resource industries, a total of more than 400 resource-based cities have been created across the country, making indelible contributions to the early industrialization and urbanization construction after the founding of the People's Republic of China ${ }^{[1-2]}$. Resource-based cities have a certain degree of particularity. On the one hand, they are established, developed and prospered due to the possessed abundant resources, but decline with the gradual exhaustion of resources, reflecting their high dependence on resources and simplification in industrial structure. On the other hand, because resource-based enterprises depend on spatial distribution of resources in location and layout, coupled with the extensive development model, problems such as the separation of industry and city and the destruction of ecological environment have become all the more serious ${ }^{[3-4]}$. According to statistics, $60 \%$ of the national energy consumption derives from resource-based cities ${ }^{[5]}$. The per capita carbon emissions of resource-based cities are twice that of national average, and the carbon emission intensity per unit of GDP is 1.5 times higher than the national average ${ }^{[6]}$. By optimizing and adjusting the city's industrial layout, land use, road traffic, and ecological environment, low-carbon-oriented spatial planning can "lock" the carbon source, carbon sink to a certain extent from the source, thereby creating low-carbon human settlements ${ }^{[7]}$. Therefore, for the research object of resource-based cities, how to put forward a targeted low-carbon planning strategy based on the discipline of urban and rural planning and promote its low-carbon transformation and development carries 
important theoretical and application value ${ }^{[8-10]}$.

According to the different research levels, domestic and foreign research is mainly carried out from the two levels of regions and towns. Low-carbon planning methods at the regional level mainly include: low-carbon optimization of land use structure, industrial structure transformation, reasonable determination of the scale of cities and towns, corridor-style development models of public transportation, and improvement of ecological carbon sinks. For representative studies: Zomer et al. built a land use structure optimization model to mitigate climate change from the perspective of land use structure optimization ${ }^{[11]}$. Catarina believed that low-carbon industries should focus on two aspects: industrial structure adjustment and industrial technology upgrading ${ }^{[12]}$. Bourne et al. believed that low-carbon city planning should focus on the interaction between the various components of the urban spatial structure, such as the determination of reasonable city scale, the relationship between regional transportation and land use, etc. ${ }^{[13-14]}$. Low-carbon planning methods at the town level can be traced back to the theory of new urbanism, smart growth theory, and compact city theory. Early theoretical research has provided a theoretical basis for the proposal of low-carbon planning methods at the town level. Specifically, it mainly includes: compact and intensive land use and mixed development, job-housing balance, higher accessibility of public transportation, commerce, and employment, encouragement towards and support of public transportation and slow traffic, increased carbon sinks and mitigated "heat island" effect, etc. ${ }^{[15]}$. For representative studies: Bartholomew et al. believed that compact urban development can significantly reduce the use of cars. In particular, after the basic balance of job and housing, it can reduce vehicle mileage by about $17 \%$ on the existing basis ${ }^{[16]}$. Gustavo proposed specific low-carbon urban spatial layout models characterized by high density, compactness, mixed land use, and diversity, and recommended the use of sustainable urban form matrix to evaluate the contribution of different elements ${ }^{[17]}$.

At present, domestic research on low-carbon planning methods started relatively late, mostly experiencing the stage of concept introduction and idea advocacy. There is need to further strengthen empirical research and method innovation. For example, at the regional scale, the low-carbon planning of the regional land use structure should, considering the current focus on land use types and intensity changes in carbon emissions accounting, strengthen the dual consideration of energy consumption and carbon emissions of human activities on different land types. At the town scale, we should strengthen quantitative research on the assessment of carbon reduction potential of low-carbon planning, and at the same time, conduct in-depth exploration into the joint carbon reduction mechanism based on coupling of the city region and the central city through scientific evidence. Therefore, this research takes low-carbon as the goal orientation, explores the important scientific theoretical issue regarding internal mechanism of low-carbon spatial planning in resource-based cities, analyzes the complex characteristics in resource-based cities' carbon emissions, and establishes low-carbon planning method for resource-based cities from the two levels of city region and central city. Moreover, empirical research is carried out based on the case of Xingtai City, a typical resource-based city, to provide theoretical and technical decision support for the future low-carbon development and completion of carbon emission reduction targets of resource-based cities.

\section{Material and Methods}

\subsection{Overview of the study area}

Xingtai City is located in the southern part of Hebei Province in North China. It is an important steel production base in China and an important power and coal production base in North China, which belongs to a typical resource-based city. For a long time, relying on its rich coal, steel and other mineral resources advantages, Xingtai vigorously develops mineral resource mining and processing industries, which has boosted the rapid economic development of Xingtai City, but has also caused serious social, economic and ecological environmental problems. For example, the unbalanced industrial structure leads to prominent problems of high energy consumption and high pollution; the urban land use structure is biased towards "heavy industries", and the proportion of industrial, mining land and urban construction land is basically balanced; the central urban land use structure is out of balance, 
showing serious job-housing separation; communication between cities and towns is inconvenient, with low public transportation share rate. At the end of 2014, the total number of vehicles owned by the citizens was 708,222. Where, the number of operating public buses was only 1066, which is a relatively low proportion, far below the national designated standard of more than 8 public bus (electric) vehicles per 10,000 people. The road network layout in the central city needs to be improved. There is serious urban ecological environment pollution; the small-scale green space in the central city in uneven spatial distribution results in limited carbon sinks. Although in recent years, the ecological environment construction and carbon sink capacity of Xingtai's central city have been greatly improved, there is big gap between total green space amount and the per capita green space index in the national standard. The per capita green area of parks is only 3.81 square meters per person, which is much lower than 8.0 square meters per person designated by "Standard for Urban Land Classification and Planned Construction Land (GB50137-2011)". Therefore, to achieve low-carbon transformation and development, Xingtai City must adjust and upgrade its industrial structure, and at the same time, conduct systematic analysis from the aspects of transportation, space, and ecology to facilitate the implementation of low-carbon transformation and development goals.

\subsection{Delineation criteria for resource-based cities}

The initial definition of resource-based cities originated from the concept of mining towns proposed by Aurousseou in the United Kingdom. After that, Harris further proposed in 1943 that if a city's mining employment population accounts for more than $15 \%$ of the city's total employment population, it can be considered as a mining city ${ }^{[18]}$. On the basis of the above research, the State Development Planning Commission proposed that resource-based cities are cities where resource-based industries occupy a large share of industries. The delineation criteria can be decided based on the proportion of resource-based enterprises' output value in total industrial output value. On the basis of the above-mentioned research, the State Council further issued the "Notice of the State Council on Printing and Distributing the National Sustainable Development Plan for Resource-Based Cities (2013-2020)" (hereinafter referred to as the "Notice"), which defines resource-based cities as cities taking exploitation, processing of natural resources such as minerals in the region as leading industries. According to the definition, there are currently 262 resource-based cities in China, of which Xingtai City is one of the five prefecture-level resource-based cities in Hebei Province.

\subsection{Determination of low-carbon planning elements for resource-based cities}

Seen from carbon emission sources of resource-based cities, there are certain similarities with other types of cities. The difference lies in the composition of carbon emissions within the city and the different proportions of different components ${ }^{[19]}$. For example, Liu Shengbin calculated the carbon emissions of industrial energy activities in 113 prefecture-level resource-based cities nationwide in 2012, and compared it with the national average level, finding that the national average level of carbon emissions from industrial energy activities accounted for $68 \%$ of the national average level of carbon emissions from energy activities, and the average level of carbon emissions from industrial energy activities in resource-based cities accounted for $84 \%$ of the average level of carbon emissions from energy activities in resource-based cities, which is much higher than the national average level ${ }^{[20]}$. Therefore, according to the "2006 IPCC National Greenhouse Gas Inventory Guidelines", there are five main sources of carbon emissions from human activities, namely energy activities, industrial production processes, agriculture, land use change and forestry, and waste treatment ${ }^{[21]}$. Based on the core content of land and space planning, this paper proposes that the core planning elements in low-carbon planning of resource-based city include four types: industrial transformation, land use, road transportation and ecological environment ${ }^{[22]}$, and there are a total of 16 planning elements. 


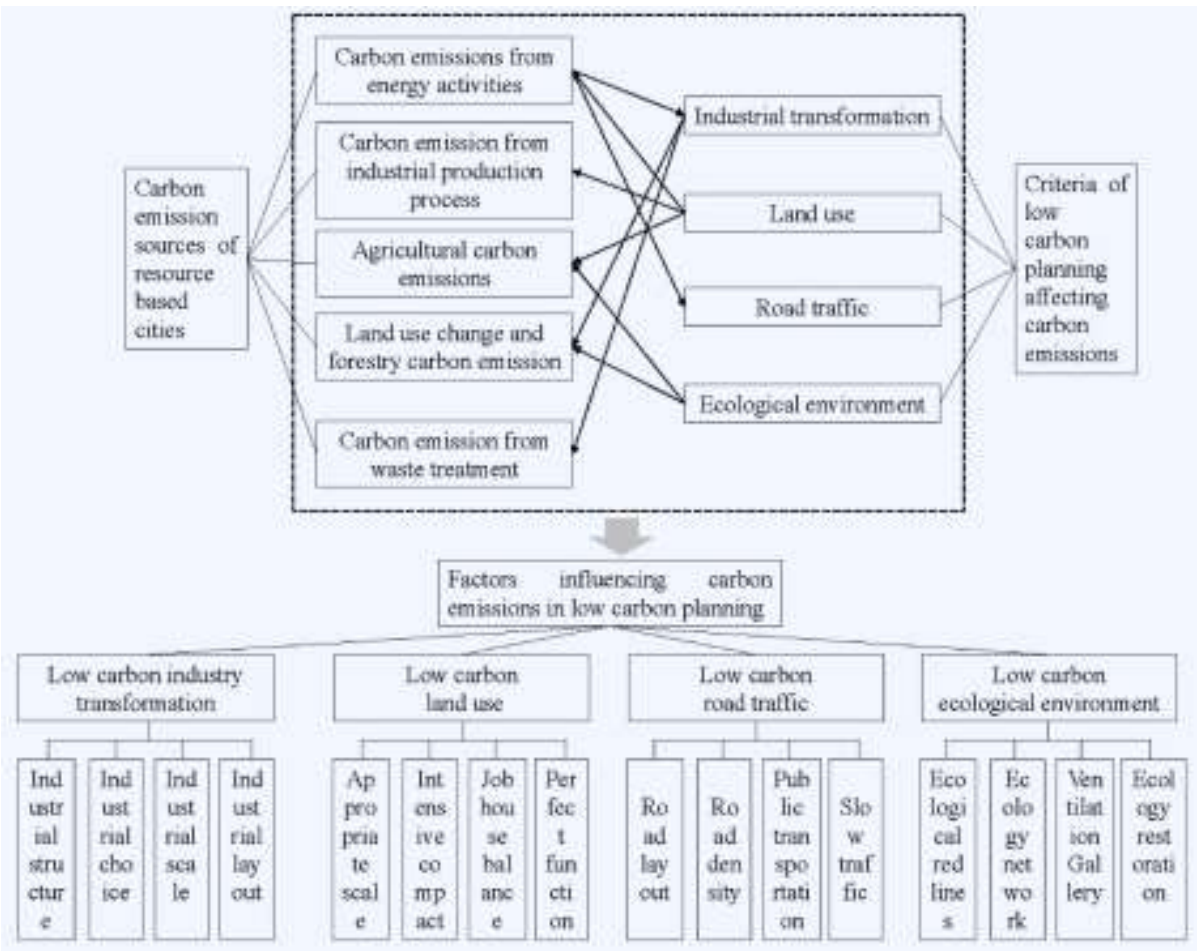

Figure 1 Low carbon planning elements of Resource-based cities

\subsection{Low-carbon planning methods for resource-based cities}

Based on the low-carbon planning elements of resource-based cities, the low-carbon planning methods of resource-based cities mainly proceed from increasing carbon sinks and reducing carbon sources. From the two levels of city region and central city, it is carried out from four aspects: industrial transformation, spatial structure optimization, road space optimization and ecological space optimization.

\subsubsection{Low-carbon planning at the city region level}

(1) Industrial transformation and optimization

Industrial energy carbon emissions are the main source of carbon emissions in resource-based cities. Spatial planning encourages the development of low-carbon industries by adjusting the industrial structure and types in resource-based cities, which can promote the low-carbon transformation and development of resource-based cities to a certain extent. In addition, on the basis of optimizing the industrial structure, we should also rationally determine the industrial development scale, optimize the industrial layout to further reduce carbon emissions. Where, the industrial scale of resource-based cities should be determined based on the government's carbon reduction targets, which should give comprehensive considerations to existing industrial development foundations, resource reserves, and population growth. Industrial layout optimization must give consideration to the comprehensive influence of factors like infrastructure carrying capacity, topography, basic farmland, so that reasonable spatial layout of different industry types can be obtained based on land suitability evaluation and the current industrial park layout.

(2) Spatial structure optimization

Spatial structure optimization at the city region level is mainly achieved by rationally delimiting the production, living and ecological space and formulating feasible space control measures. On the one hand, it is to optimize the relationship between the central city and the peripheral towns, surrounding mountains, forests and other natural resources, guarantee a reasonable urban development and construction scale and the most basic carbon sink function in the city, thereby optimizing the urban spatial pattern; on the other hand, it is to coordinate relationship between production, life and ecological space to maximize the carbon reduction benefits of production, living and 
ecological space.

\section{(3) Road traffic optimization}

Due to historical reasons, China's resource-based cities have experienced a period of rapid development from small to big, or even from nothing, making the railways and high-grade highways outside the towns become transit traffic within the towns, which brings a significant negative impact on the development of resource-based cities. On the one hand, the transit traffic passes through the city region, causing more vehicles in the urban area, leading to serious congestion, and poor traffic environment. On the other hand, the transit traffic splits the urban functions, causing major changes in the development direction of urban space, and bringing inconvenience to residents' travel. Therefore, low-carbon planning of resource-based cities must deal with the connection between external transportation and urban transportation to meet the low-carbon transformation and development needs of resource-based cities.

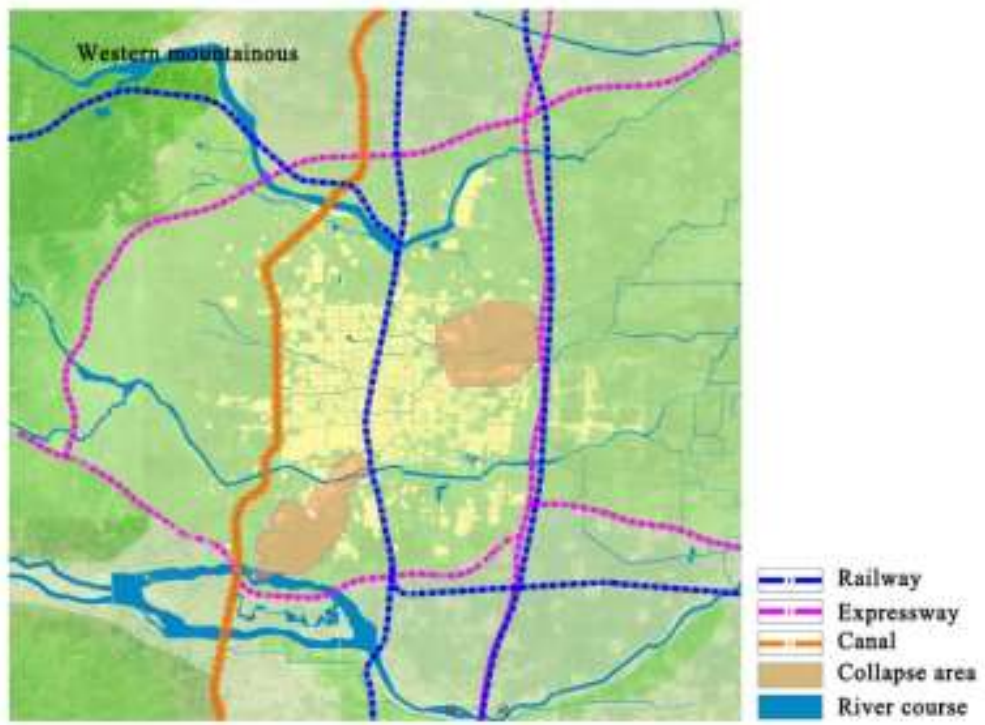

Figure 2 The relationship between Beijing-guangzhou railway and Xingtai central city

\section{(4) Ecological environment optimization}

Compared with scattered ecological patches, continuous ecological network space has stronger carbon sink capacity. Therefore, low-carbon planning of resource-based cities should give consideration to carbon sink capacity and spatial distribution characteristics of different green space spaces, build a carbon sink network consisting of green land patches-ecological carbon sink corridors-peripheral carbon sink matrix based on ecological restoration. In this way, by connecting different types of ecological patches as an organic whole, and taking into account the surrounding ecological environment of the city, carbon sink capacity is increased.

\subsubsection{Low-carbon planning at the central city level}

(1) Spatial structure optimization

To a certain extent, compact and intensive high-density urban space can effectively lower per capita carbon emissions of transportation and travel, thereby reducing urban carbon emissions to a certain extent. In low-carbon planning of resource-based cities, we should conduct research on the carbon emissions of different land types and analyze gradient attributes of carbon emissions from different land types, thereby completing current carbon emissions measurement of the central city area and using it as the basis and prerequisite for reasonable layout optimization. Based on mandatory requirements for the total amount, we can propose corresponding low-carbon space optimization strategies for the urban spatial structure, industry, transportation, commerce and public service facilities ${ }^{[23-24]}$. When analyzing the gradient attributes of carbon emissions from different land types, this paper 
takes reference data and scoring method to determine the carbon emission factor data of various land types as a reference $^{[25-26]}$, as shown in the following table:

Table 1 Carbon emission coefficient of land use

\begin{tabular}{cccc}
\hline $\begin{array}{c}\text { Primary } \\
\text { classification }\end{array}$ & $\begin{array}{c}\text { Secondary classification } \\
\text { (Urban land classification) }\end{array}$ & Main carbon emission activities & $\begin{array}{c}\text { Carbon emission } \\
\text { factor(t/hm2) }\end{array}$ \\
\hline $\begin{array}{c}\text { industry } \\
\text { facilities space }\end{array}$ & Industrial land & goods-producing industry & 158.85 \\
& Land for public facilities & $\begin{array}{c}\text { Heat supply, water supply, power } \\
\text { supply and gas supply }\end{array}$ & 8.00 \\
traffic & Road and transportation & Waste disposal & 8.00 \\
fransportation & facility land & Urban road transportation & 29.00 \\
space & Land for logistics and & Ancillary facilities & 29.00 \\
& warehousing & Carbon emissions from material & 29.00 \\
storage, transit and distribution & 10.78 \\
public & Public management and public & Administrative office, education, & medical treatment and sanitation, \\
service space & service land & etc. & 2.10 \\
& Land for commercial service & Commercial leisure & 2.10 \\
Resident living & facilities & Culture and entertainment & 2.10 \\
space & Residential land & Urban residential land & 10.50 \\
Green space and & Green space and square land & Garden and green space & -0.40 \\
Water area & Water area & Rivers, lakes & -0.40 \\
\hline
\end{tabular}

(2) Reasonably optimize the layout of urban residence and employment space to achieve job-housing balance Resource-based cities have single construction land function. In particular, industrial areas rely on the distribution of resources, leading to loose structure and long distance from the residential center of the city, causing excessive long-distance commuting traffic. In low-carbon planning, we should give comprehensive consideration to brownfield reuse, etc., rationally arrange production and living land, optimize the layout of urban industries, and promote job-housing balance to avoid excessive long-distance commuting traffic.

(3) Improve road planning systematicness in central city

Resource-based cities represent a special city type in the era of industrial development. The over-satisfaction of freight demand in urban road traffic planning has led to extremely unbalanced road network construction, ignoring human travel needs. Therefore, in low-carbon planning, we should first attach importance to the systematicness, hierarchy and completeness of the road network system in the central city. Secondly, we should draw lessons from typical domestic and foreign low-carbon city planning practices, reasonably determine road class, spacing and road network density in resource-based cities based on development stage of the city, and advocate the development model of "narrow road in dense network". Third, form a complete public transportation network system and transfer system through planning, improve the city's public transportation travel ratio and public transportation environment, and finally achieve the goal of energy conservation and emission reduction ${ }^{[27]}$. Finally, in view of the functional characteristics of different areas in resource-based cities (such as commercial districts, residential areas, parks, etc.), establish a continuous bicycle transportation network with seamless transfers between bicycles and public transportation to improve the pedestrian traffic environment in accordance with local conditions. Slow traffic should be encouraged.

(4) Establish ecological carbon sink corridors and give full play to its role

Since old town development and construction has been relatively mature in resource-based cities, it is difficult to reserve sufficient space to build large-scale ecological green space. Therefore, in low-carbon planning of resource-based cities, we should pay attention to the carbon sink function of linear ecological carbon sink corridor 
with small land occupation. With the help of road greening, river greening, etc., we should establish ventilation corridors inside the city to increase carbon sink capacity inside the city. Moreover, the ventilation corridor is able to introduce the peripheral ecological space into the city, optimize the city's microclimate environment, and promote energy conservation and emission reduction.

\section{Results and discussion}

3.1 At the municipal level, increase carbon sinks and reduce carbon sources via spatial structure optimization

3.1.1 Industrial structure transformation and optimization of Xingtai City

At the city region level, Xingtai City should actively expand the resource-based industrial chain, and vigorously develop new succeeding leading industries based on the development positioning of different towns and new districts. At the same time, Xingtai New District and other industrial parks in the central city should be used as core carriers to actively cultivate emerging industries such as new energy and new materials, with focus on the construction of equipment manufacturing industrial park clusters and providing various conveniences for clusters. By relying on large enterprises and large projects to vigorously develop circular economy, we should gradually eliminate related industries with coal as a means of production. For traditional industries, we should force the transformation and upgrading of traditional industries by meeting environmental protection standards and accelerating the elimination of outdated production capacity.

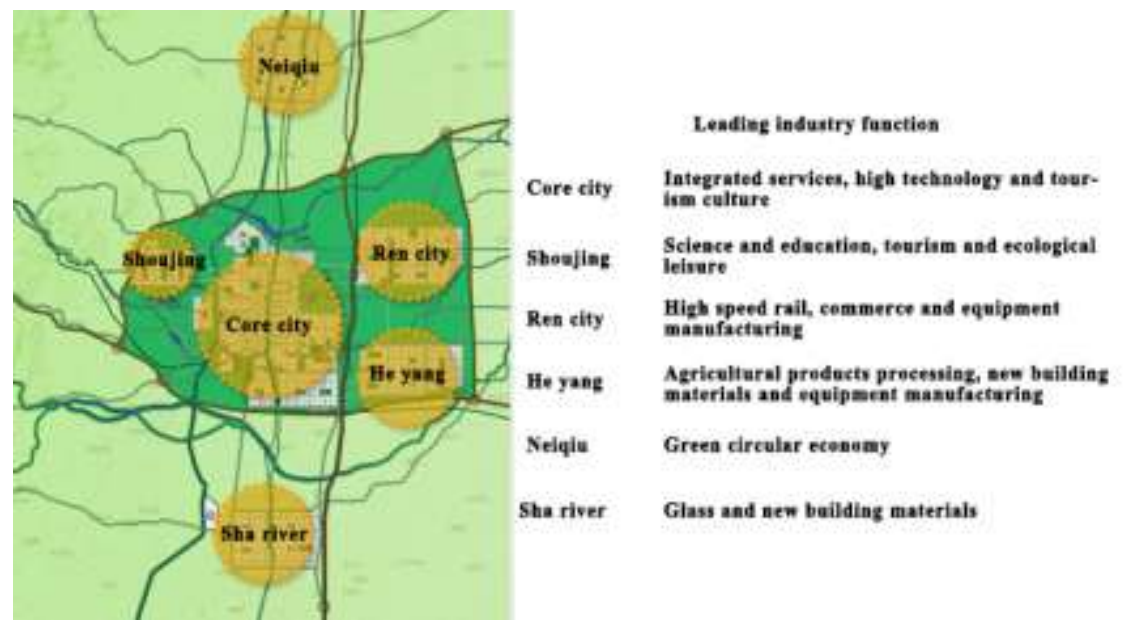

Figure 3 Xingtai City leading function block diagram

3.1.2 Spatial optimization of land use structure in Xingtai City

In terms of reducing carbon sources, the production and living spaces are organized in the form of "organic clusters" based on ecological space. By forming urban living space with the central city as the center and five county towns as the main living groups, optimize and upgrade the original production space, develop pollution-free advanced manufacturing industry, and focus on building two major industrial clusters in Fuyang and Sanzhao in the future. This not only facilitates transformation and upgrading of resource-based Xingtai City, but also achieves the goal of effectively controlling carbon sources in the city. In terms of increasing carbon sinks, the city region takes the Taihang in the west and the vast agricultural space in the east as the main ecological space to penetrate into the central urban cluster space. Through the management, control and protection of the ecological space, it can greatly accelerate establishment of compact Xingtai City and implementation of carbon reduction goals. 


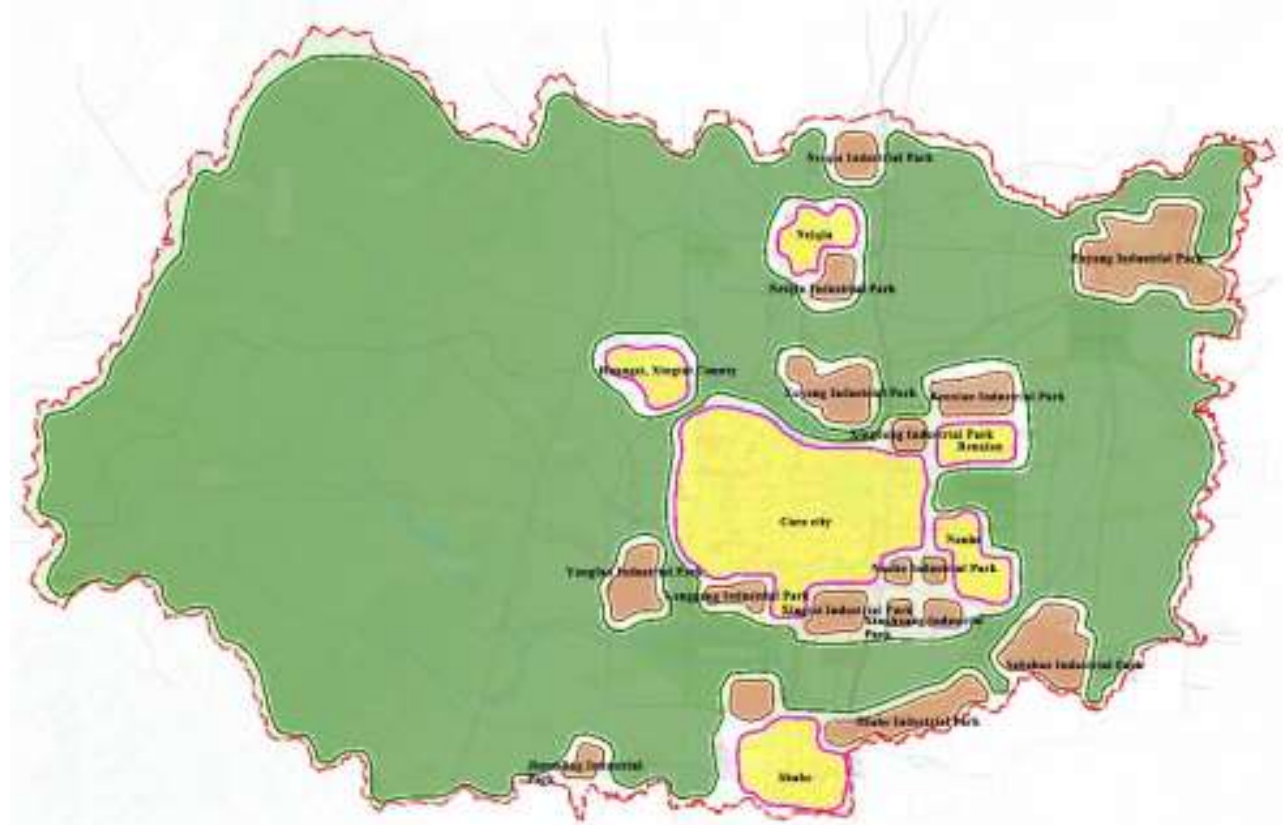

Figure 4 Sansheng space organization plan of Xingtai City

3.1.3 Optimization of low-carbon transportation space in Xingtai City

It is necessary to strengthen intra-city connections between cities and towns, establish bus corridors, and improve the city's comprehensive transportation network. Major public facilities are shared through public transit corridors to form a rationally structured urban agglomeration system. There is need to fully consider the connection between the central city and the satellite towns, establish a city-wide bus corridor, promote the integrated development of the central city and five satellite towns, connect the existing and future major nodes, increase the bus sharing rate while ensuring passenger, thereby reducing carbon emissions.

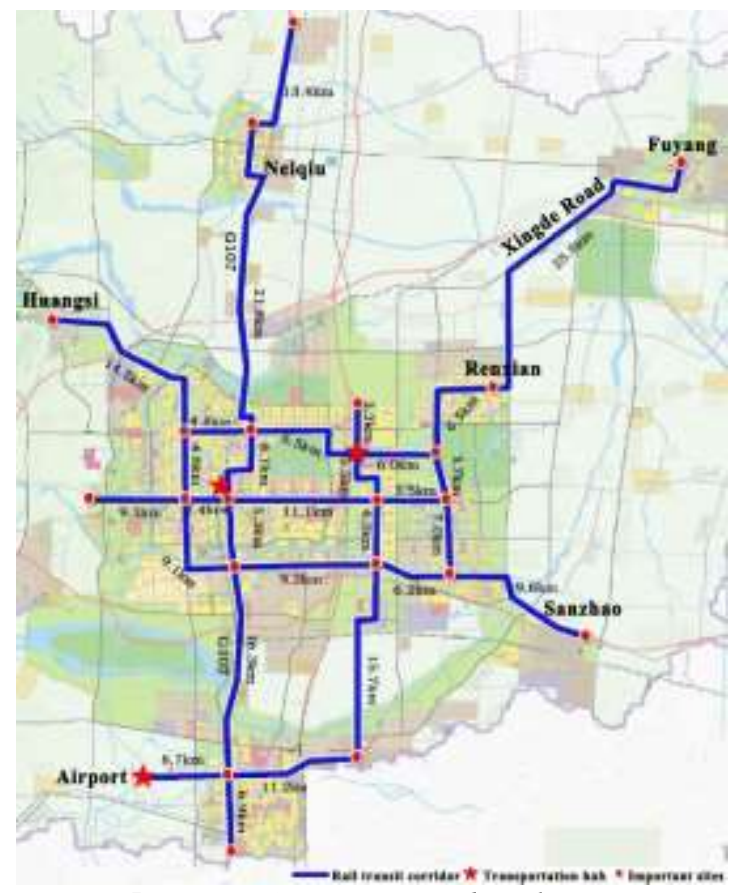

Figure 5 Xingtai City Bus corridor planning 
3.1.4 Ecological space optimization and adjustment in Xingtai City

By comprehensively considering the differences in the spatial distribution of the social, economic and ecological environment of Xingtai City, plus the impact of various ecologically sensitive areas, ecological corridors are built based on rivers to connect "mountains, waters, cities and fields" and form an ecological network pattern, thus dividing Xingtai City into the Western Taihang Mountain Ecological Zone and two first-level functional zones of Central and Eastern Plain Ecological Zones. Where: the western mountainous area has good vegetation coverage, which is the main distribution area of a variety of precious animals and plants, mainly for ecological conservation. The central city adheres to ecological restoration and rational development, which constitutes the unique water system ecological landscape of Xingtai City. The east area develops multifunctional new agriculture along the river by actively incorporating basic farmland into the ecological security pattern, thus building farmland with single planting function into a new type of urban agriculture with multiple functions: ecological maintenance, landscape culture, sightseeing and leisure, social security.

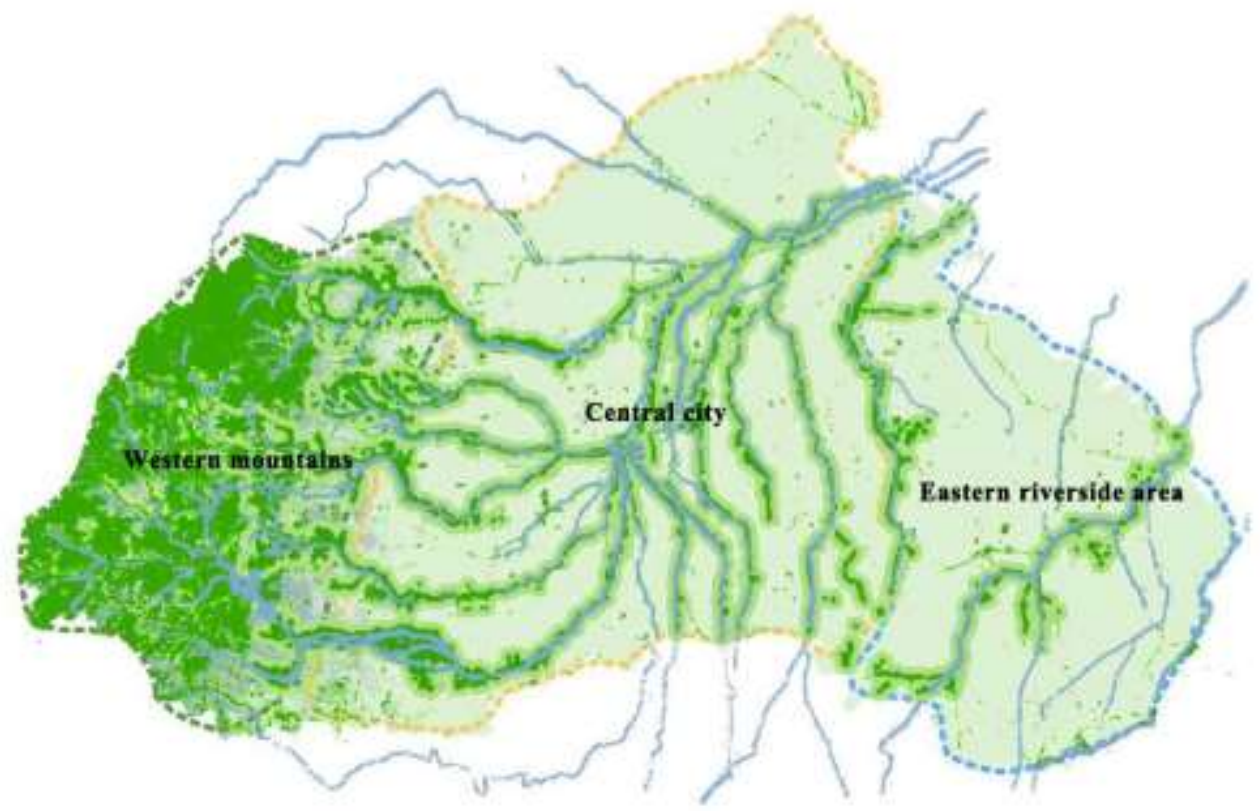

Figure 6 Ecological function regionalization of Xingtai City

3.2 Spatial structure optimization of Xingtai City at the central city level

3.2.1 Perfect the adjustment of urban spatial structure to promote high-density urban development

At the central city level, first of all, Xingtai City should focus on optimizing the spatial relationship between industry, warehousing logistics, and transportation stations. In Xingtai City, a resource-based city, most freight transportation comes from storage, industrial transportation, etc. Therefore, distribution of storage, industrial land and external transportation stations is an important factor affecting transportation carbon emission factors. It is planned to set up two passenger transportation centers in the downtown area of Xingtai City, namely Xingtai Railway Station and Xingtai East High-speed Railway Station. Also, a freight center will be set up in the southern part of the central city. The layout of the warehouse and logistics center should approach the main external transportation stations and external artery traffic as close as possible to form a certain scale in distribution and adjoin the industrial area. Secondly, the commercial space structure is optimized. The plan is to form a three-level commercial structure system consisting of a regional commercial center, a secondary commercial center, and a commercial belt along the street. Specifically, the primary commercial center includes Xingtai Central Business District and municipal traditional commercial centers; secondary commercial center includes seven district-level commercial centers, namely, Longgang District Commercial Center, Shangdong District Commercial Center, Vocational Education District Commercial Center, Steel Railway Area Commercial Center, Development Area Commercial Center, Wangkuai Area Commercial Center and the south commercial center of the high-speed 
railway area; as well as the commercial belt along the main roads in the area.

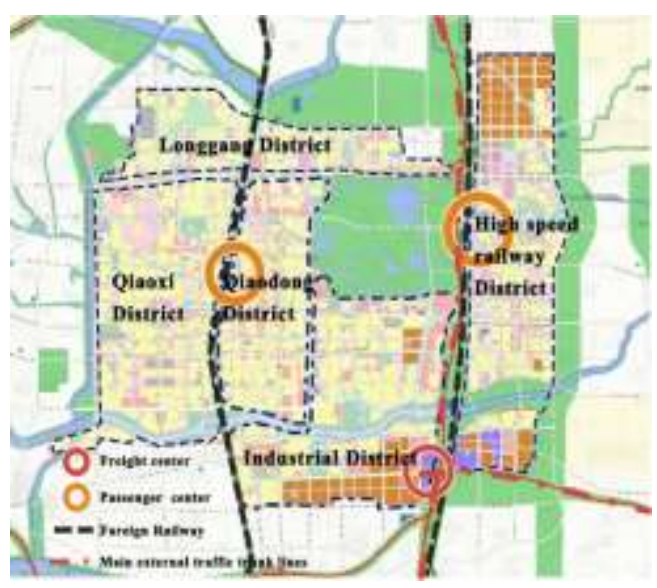

Figure 7 Optimization of the relationship between industry, warehousing, and transportation stations

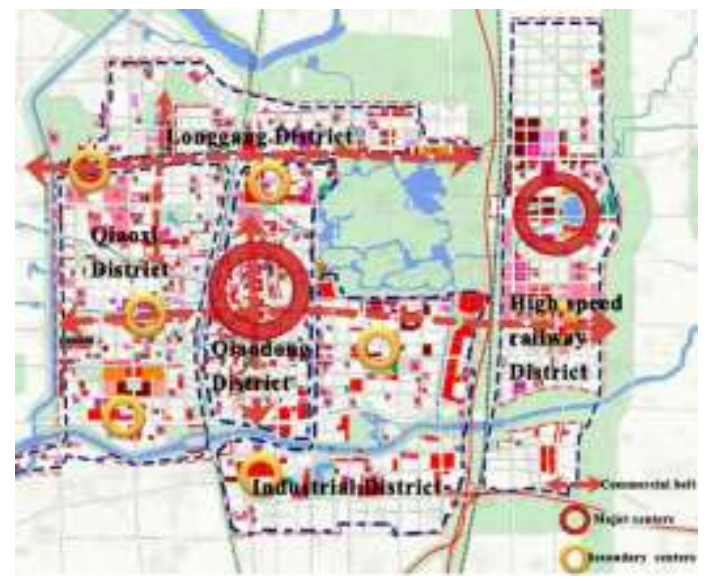

Figure 8 Business structure optimization

Finally, we come to space optimization of public service facilities. A modern administrative and cultural center will be planned in the high-speed railway area in the east of Xingtai, and large-scale administrative and cultural facilities of good quality in the Qiaoxi area will be retained to form an urban administrative and cultural center. At the same time, five administrative and cultural sub-centers of Longgang area, Qiaoxi area, Qiaodong area, development area and high-speed railway area will be formed. 


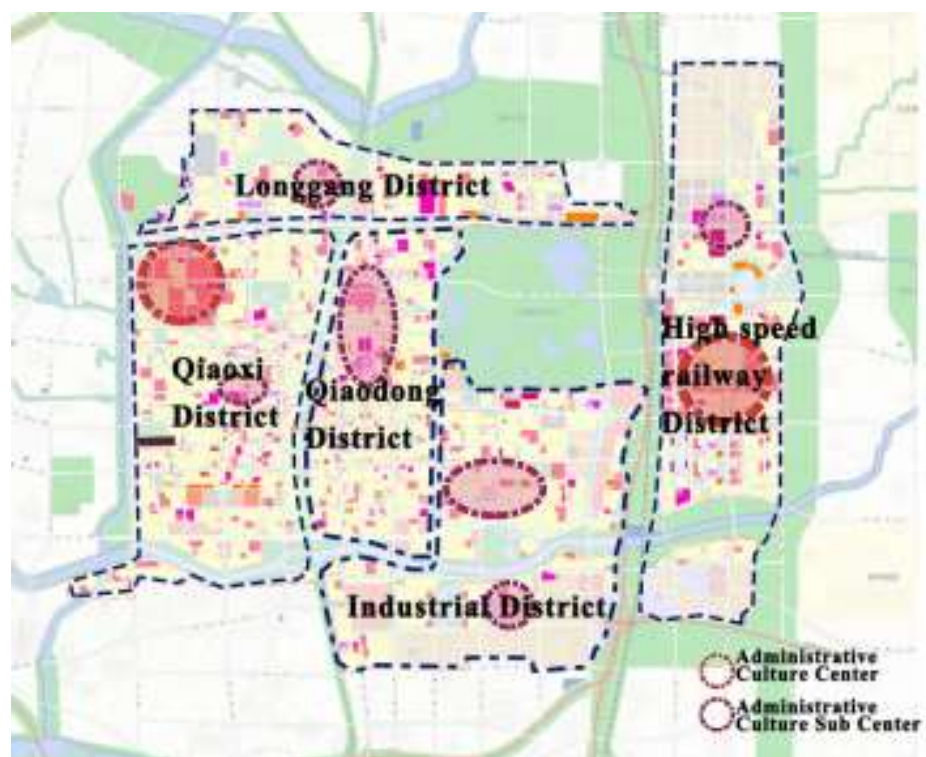

Figure 9 Space optimization of public service facilities

3.2.2 Optimize the job-housing space to improve service capacity of transportation facilities

It is necessary to strengthen the relationship between industrial layout and residential land. At the same time, within each district of the central city, reasonably distribute the residential space and employment space of the five districts: Zhonglonggang area, Qiaoxi area, and Qiaodong area. In the planning of the high-speed railway area and the development area, sufficient residential land and supporting facilities are reserved to achieve a dynamic balance between employment space and residential space, thereby reducing the huge traffic flow generated by the commuting of the population in the central city and achieving the goal of effective carbon reduction.

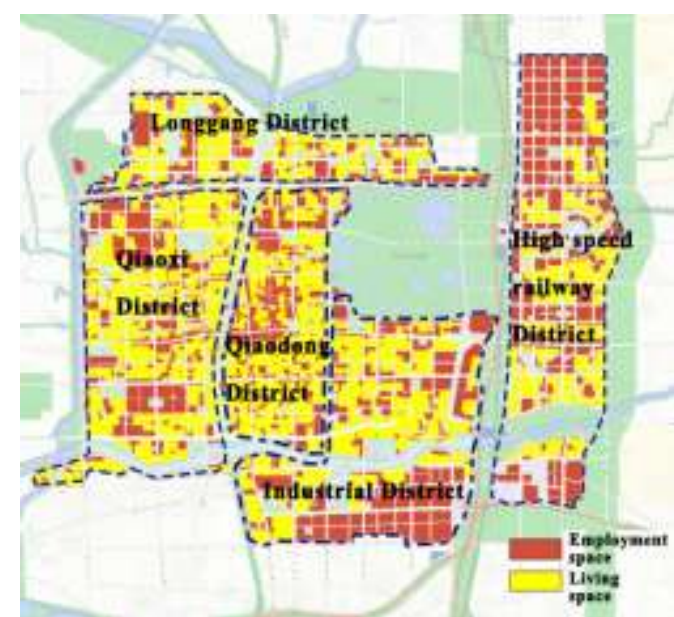

Figure 10 The relationship between planning employment and planning residence in central city 


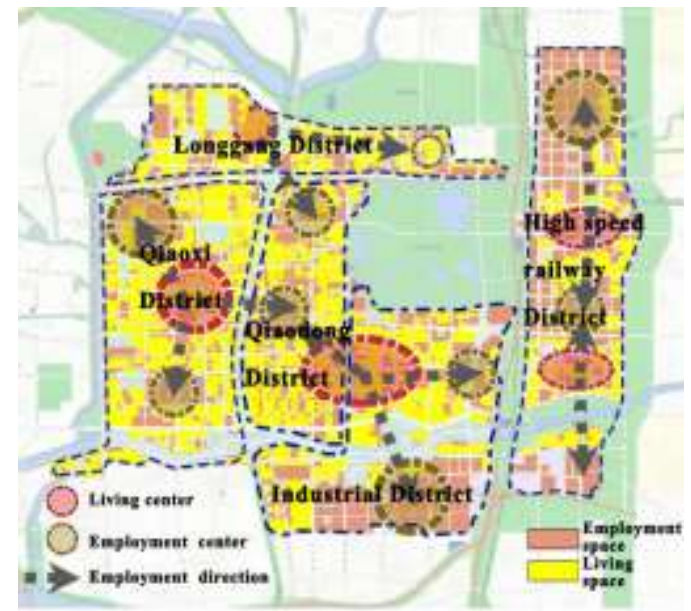

Figure 11 Optimization of job housing balance in central city

3.2.3 Optimization of low-carbon transportation space

As Beijing-Guangzhou Railway passes through the central city, there is inconvenient connection between the roads on both sides of the railway, with many broken road ends, many oblique roads, and many misplaced roads. The focus is to optimize the connection of the roads on both sides of the railway by increasing the connection channels. The number of main connection channels has been increased to 10 from 5, thus avoiding traffic congestion in the morning and evening rush hours. Secondly, according to the actual situation and planned spatial layout of Xingtai City, public transport network will be planned to form a full coverage public transport network based on the public transport branch line network, in which, rail transit and conventional public transport complement each other. The density of the central city's public transport network is planned to reach 3-4 kilometers per square kilometer; the coverage rate of the 300 -meter radius of the central city bus station is not less than $50 \%$, and that of the 500 -meter radius is not less than $90 \%$, so that the public transportation mode share rate exceeds $30 \%$.

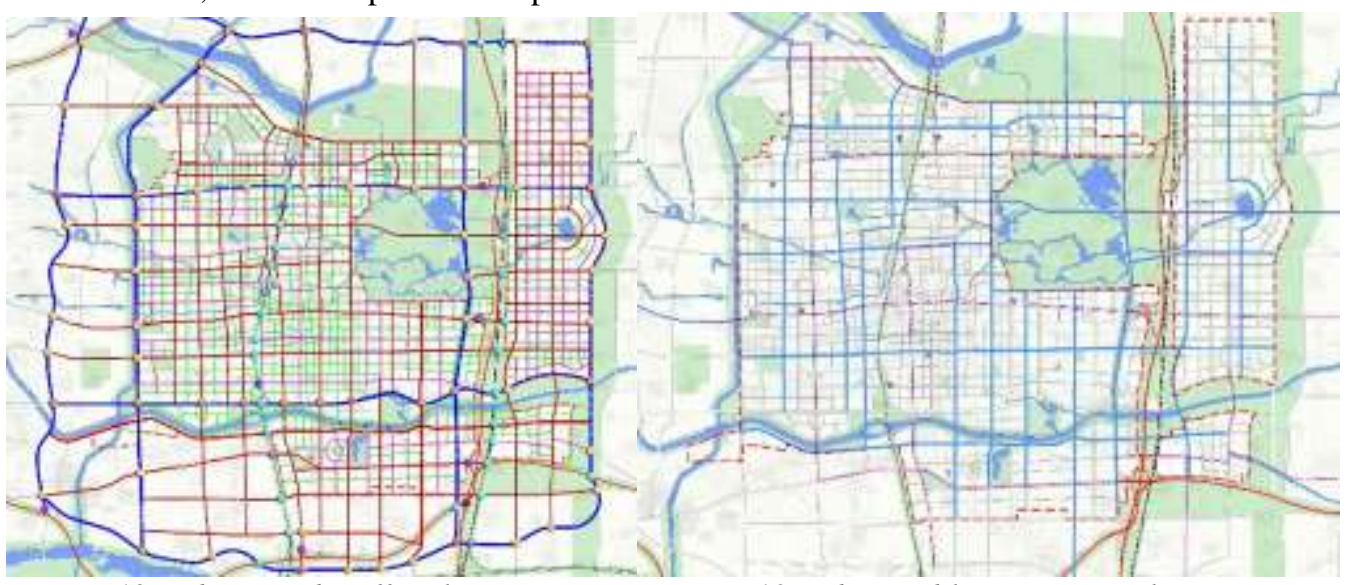

Figure 12 Urban road traffic planning

Figure 13 Urban public transport planning

The last is the optimization strategy of urban slow traffic system. The focus is to perfect the slow traffic system in the city square area, lakeside area and the old city commercial center area. On the one hand, we will improve the slow traffic system through the newly built roads. Attention will be paid to pedestrian on the main roads and intersections with frequent motor vehicle traffic. The slow traffic in the road section will be guaranteed by setting up separation belts or barriers, and lineation between motor and non-motor vehicles to give priority to slow traffic. On the other hand, pedestrian bridges or underpasses are built in accordance with the actual situation. Waterfront walking belts are established based on waterfront landscapes with beautiful natural scenery. 


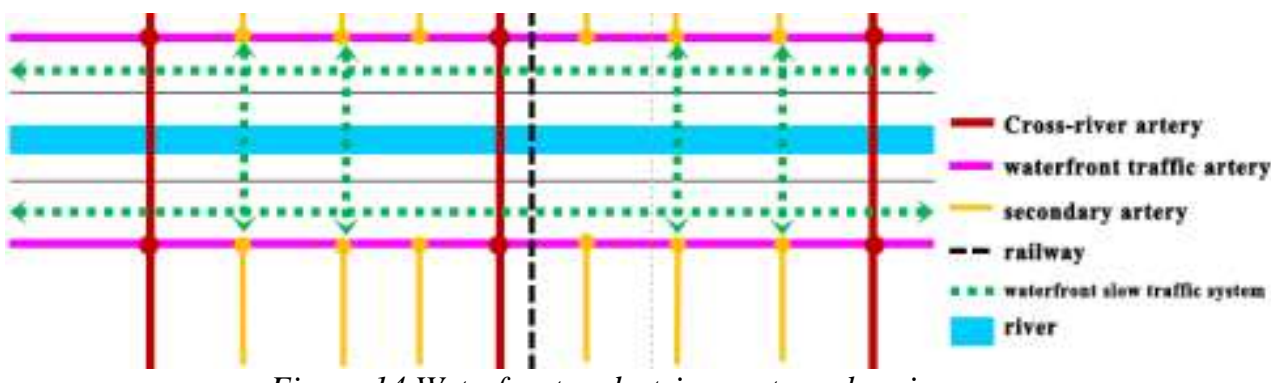

Figure 14 Waterfront pedestrian system planning

3.2.4 Ecological network optimization

We should build a green layout structure in the central city, and establish a hierarchical park system. By using water systems, regional transportation facilities, large-scale sites, and land unsuitable for construction to create a rural ecological green space system, it is possible to form a green base for the central city. On the one hand, it can be used as an urban ecological corridor to promote urban ventilation and effectively improve air quality. On the one hand, it can also be used as an ecological isolation between the central city and surrounding towns, thus playing a role in providing high-quality greening environment and controlling space sprawls. The green space system in the central city takes the central ecological park as the ecological green core, and the belt-shaped green space along the river and the road as the link, thus forming a green layout structure characterized by "one heart, six corridors, ten axes, and multiple nodes". City-level comprehensive parks and district-level comprehensive parks constitute the main body of the green space system in the central city of Xingtai, which is supplemented by specialized parks and belt-shaped parks formed by the waterfront to form a hierarchical and functional green space system that can greatly improve the city's capacity in reducing emission reduction and increasing carbon sink.

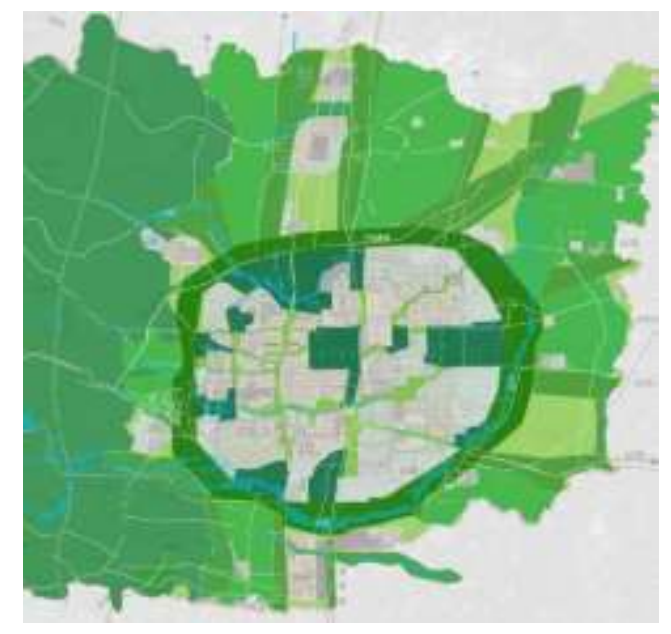

Figure 15 Park system optimization in central city 


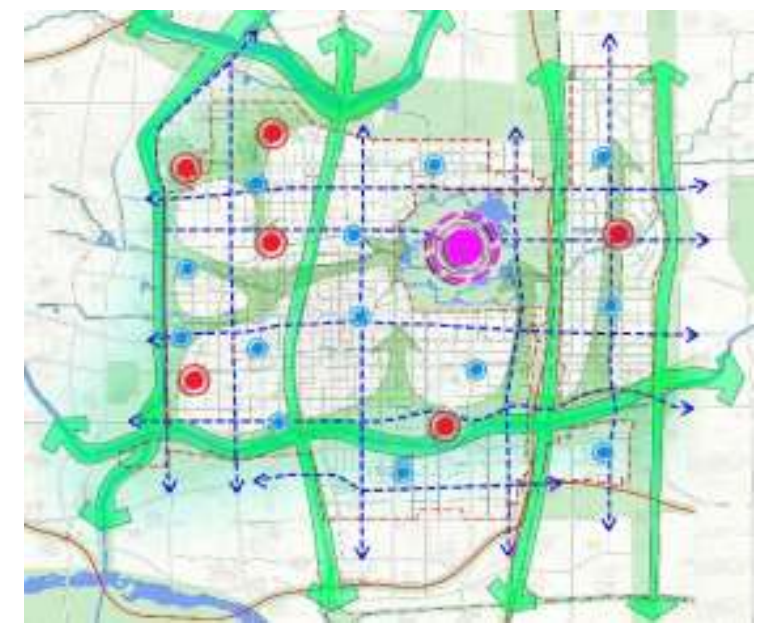

Figure 16 Green space system optimization in central city

\section{Conclusion}

In the era when the country is striving for "carbon peak" and "carbon neutrality", how to promote the low-carbon transformation and development of resource-based cities has gradually become an important topic. Research has shown that spatial layout has a "locking" effect on carbon emissions. Therefore, based on the city region and central city levels, this paper proposes low-carbon planning for resource-based cities from the four aspects of industrial transformation, land use, road traffic and ecological environment. It is considered that at the city region level, Xingtai City should vigorously develop Xingtai East New District as a platform for industrial transformation and upgrading, weaken the position of coal-related industries as the leading industry, rationally delimit the production, living and ecological space, establish a city-wide bus corridor, and strictly control the city-wide ecological space. At the central city level, Xingtai City should improve the urban spatial structure, promote high-density urban development, optimize job-housing space, slow traffic systems, public transportation systems, and ecological spaces. By exploring the application of low-carbon spatial planning in low-carbon transformation and development of resource-based cities, on the one hand, it can provide forward-looking, advanced, and operable guidance and specific implementation path references for the low-carbon transformation and development of resource-based cities. On the other hand, taking Xingtai as a case city, it also carries certain reference and reference significance for the low-carbon transformation and development of similar cities.

\section{References}

[1] Zhou Min, Chen Hao. "A preliminary study on the spatial patterns, problems and planning countermeasures of resource-based cities”. Modern Urban Research, 201(7), pp. 55-59.

[2] Tian Yan, Su Wenlong, Zhang Liwen, et al. "Spatial evolution and development optimization strategy of resource-based cities”. Planners, (9), pp. 88-93, 2014.

[3] Lu Changliang, Wang Cui. "Research on the development strategy of resource-based cities from the perspective of urban planning”. Journal of Jilin Jianzhu University, 27(1), pp. 7-10, 2010.

[4] Wu Yanxia, Deng Nan. "Ecological Security Warning for Resource-based Cities Based on RBF Neural Network Model_— Taking Yulin City as an Example”. Ecological Economy, 35(5), pp. 111-118, 2019.

[5] Sun Xiumei. "Low-carbon transition mechanism and regulation countermeasures for resource-based cities". Beijing: China University of Mining and Technology, 2011.

[6] Miao Junqiang. "Research on the construction path of low-carbon ecological transformation of resource-based cities: Taking Dongying City as an example”. Tianjin University, 2013.

[7] Han Sun, Qin Bo. "Low-carbon spatial planning and sustainable development: a study based on the survey of Beijing residents' carbon emissions”. Beijing: Renmin University of China Press, 2014. 
[8] Ishii S, Tabushi S, Aramaki T, et al. "Impact of future urban form on the potential to reduce greenhouse gas emissions from residential, commercial and public buildings in Utsunomiya, Japan”. Energy Policy, 38, pp. 4888-4896, 2020.

[9] Glaeser E L, Kahn M E. "The greenness of cities: Carbon dioxide emissions and urban development". Journal of Urban Economics, 67, pp. 404-418, 2010.

[10] Fang W K, Matsumoto H, Ho C S, et al. "Energy consumption and carbon dioxide emission in the urban planning process in Malaysia". Jounal of the Malaysian Institute of Planners, 6, pp. 101-130, 2008.

[11] Monteiro C S, Pina A, Cerezo C, et al. "The Use of Multi-detail Building Archetypes in Urban Energy Modelling”. Energy Procedia, 111, pp. 817-25, 2017.

[12] Catarina Thormark. "A low energy building in a life cycle-its embodied energy, energy need for roperation and recycling potential". Building and Environment, 37, pp. 429-435, 2002.

[13] Brotchie J. "The future of urban form”. London: Routledge. 1989.

[14] Ana simao, Paul J, Densham. "Web-based GIS for collaborative planning and public participation: An application to the strategic planning of wind farm sites". Journal of Environmental management, 90, pp.2027-2040, 2009.

[15] Cui Bo, Li Jinwei, Zheng Yangyang, Zhong Yangyan. "Application and Practice of Low-Carbon City Concept in Urban Planning___Taking Xiamen City as an Example”. Urban Development Studies, (11), pp. 113-117, 2010.

[16] Bartholomew K, Ewing R. "Land useetransportation scenarios and future vehicle travel and land consumption: a meta-analysis". Journal of the American Planning Association, 75(1), pp. 1-15, 2009.

[17] Gustavo Arciniegas, Ron Janssen. "Spatial decision support for collaborative land use planning workshops”. Landscape and urban planning, 107, pp. 332-342, 2012.

[18] Wang Ling. "Evaluation and Countermeasures of Low-Carbon Transition of Resource-based Cities". Wuhan: Wuhan University, 2014.

[19] Zomer R.J., Trabucco A., Bossio D.A., et al. "Climate change mitigation: A spatial analysis of global land suitability for clean development mechanism a forestation and reforestation". Agriculture Ecosystems \& Environment, 126(1/2), pp. 81-97, 2008.

[20] Liu Shengbin. "Research on factors influencing carbon emissions and carbon control planning strategies of resource-based cities: Taking Xingtai City as an example". Tianjin: Tianjin University, 2019.

[21] Cong Jianhui, Liu Xuemin, Zhao Xueru. "Boundary definition and measurement of urban carbon emission accounting”. China Population Resources and Environment, 24(4), pp. 19-26, 2014.

[22] Cervero R, Kockelman K. "Travel Demand and the 3Ds: Density, Diversity, and Design". Transportation Research Part D, 2, pp. 199-219, 1997.

[23] HeZX, XuSC, ShenWX, et al. "Impact of urbanization on energy related CO2 emission at different development levels: Regional difference in China based on panel estimation”. Journal of Cleaner Production, 140, pp. 1719-1730, 2017.

[24] Yang D, Feng L. "Examining the effects of urbanization and industrialization on carbon dioxide emission: Evidence from China's provincial regions". Energy, 125, pp. 533-542, 2017.

[25] Song Dan. "Low-carbon land use analysis and structure optimization of Changchun City". Changchun: Jilin University, 2017.

[26] Peng Shuai, Shan Xuejiao, Huang Yuzhou, et al. "Practice and Enlightenment of Sustainable Urban Development in Germany-Taking Eco-city Construction of Freiburg as an Example". Eco-City and Green Building, (5), pp. 43-50, 2018.

[27] Caputo P, Costa G, Ferrari S. "A supporting method for defining energy strategies in the building sector at urban scale”. Energy Policy, 55, pp. 261-70, 2013. 